\title{
PAGET'S DISEASE AT THE HIP WITH OSTEOARTHROSIS: RESULTS OF INTERTROCHANTERIC OSTEOTOMY
}

\author{
Brian A. Roper, London, England
}

From the Institute of Orthopaedics, Royal National Orthopaedic Hospital, London and Stanmore

Paget's disease of bone (osteitis deformans) is associated with deformities leading to deranged joint mechanics and ultimately to degenerative changes. There appears to be a general impression that the results of intertrochanteric osteotomy for osteoarthrosis of the hip involved in Paget's disease are indifferent. It was thought worth while to test this supposition so far as the paucity of reasonably comparable material allows.

TABLE I

Distribution of Paget's Disease

\begin{tabular}{|c|c|c|c|c|}
\hline $\begin{array}{c}\text { Bilateral, } \\
\text { pelvis }\end{array}$ & $\begin{array}{l}\text { Bilateral, } \\
\text { pelvis and } \\
\text { femur }\end{array}$ & $\begin{array}{c}\text { Right } \\
\text { hemipelvis }\end{array}$ & $\begin{array}{c}\text { Left } \\
\text { hemipelvis }\end{array}$ & Femur \\
\hline 2 & 3 & 5 & 3 & 1 \\
\hline
\end{tabular}

The literature gives little guidance. Among 144 patients with Paget's disease involving the hip joint, Chambers and Pearson (1970) recorded nine who had intertrochanteric osteotomy, with relief of symptoms in all. Nicoll and Holden (1961) reported five cases, with abolition of pain in three and improvement in two.

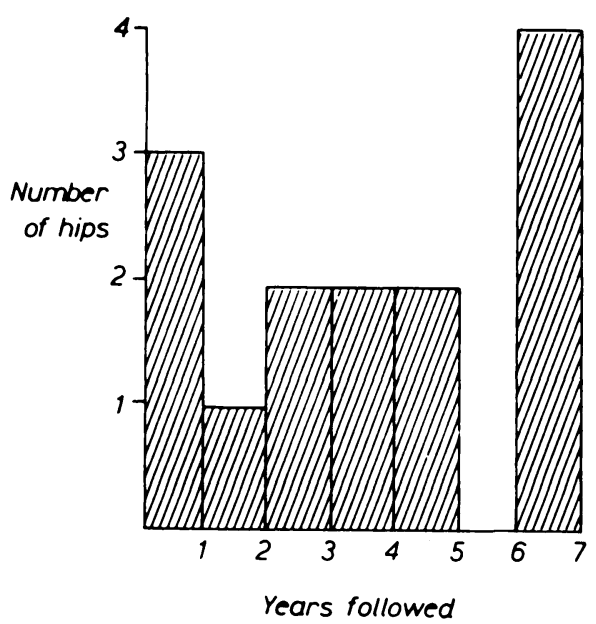

Fig. 1

Period of follow-up.

Pygott (1957), from a radiological examination of the lumbar spine and pelvis in cadavera, found an incidence of Paget changes of 3.5 per cent in subjects over forty-five years of age. Yet at the Royal National Orthopaedic Hospital, where 1,414 osteotomies were carried out for osteoarthrosis of the hip in eight years, only fifteen hips in fourteen patients were involved by Paget's disease, namely 1 per cent. The patients comprised nine women and five men with an average age of sixty-three years at the time of operation. The average duration of symptoms before operation was three years. The present report is based on this material.

The distribution of the Paget's disease is summarised in Table I. According to Fairbank's (1950) classification the bone was considered to be spongy in six cases, striated in four and dense in three, but there seemed no correlation between its type and the incidence of protrusio. In only two bilateral cases was Paget's disease equally severe on both sides of the pelvis, and in only one case were there symptoms in both hips. In the others the opposite hip appeared clinically and radiologically normal.

\section{OPERATIVE DETAILS}

The fifteen osteotomies showed medial displacement varying from none at all to a third of the diameter of the shaft. Eleven showed a varus angulation of from 5 to 20 degrees (average 
12 degrees), three were neutral and one showed valgus of 10 degrees. Internal fixation was by a straight spline in eight cases, by McKee nail-plate in five and by a modified Müller compression plate in two. There was no death, sepsis or failure to unite. No difficulty due to abnormal bone texture was noted at any of the operations.
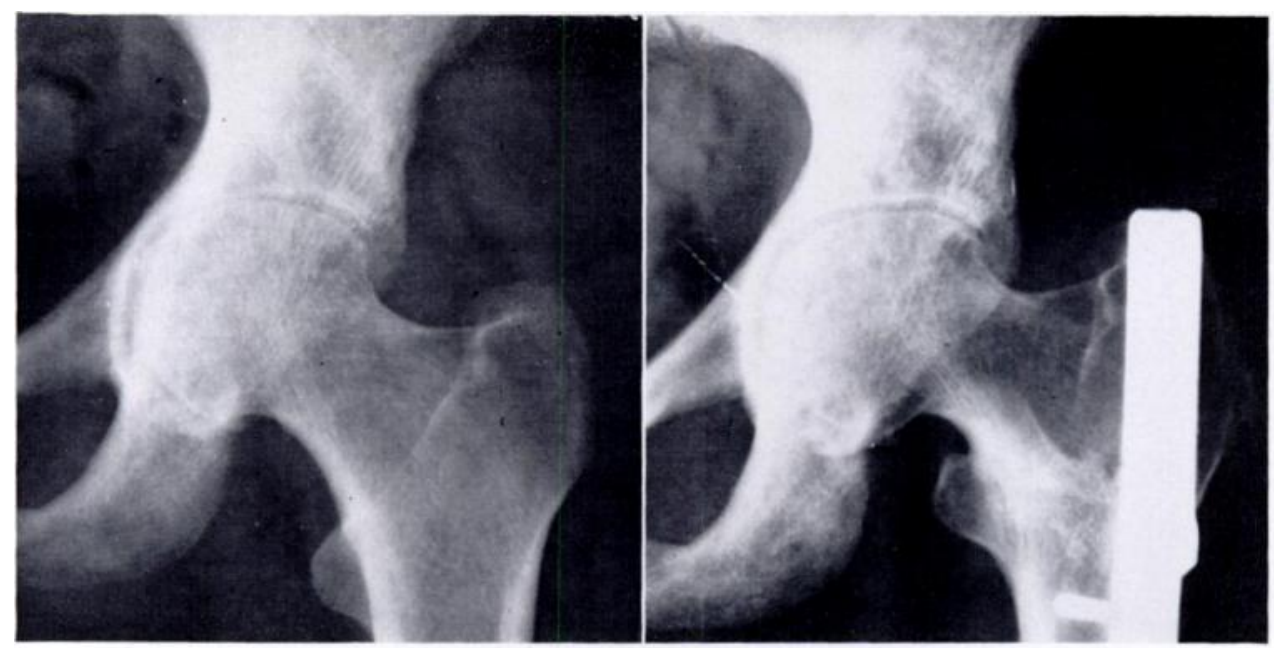

FiG. 2

Radiographs of left hip before operation and four years after operation, showing improvement in joint space.
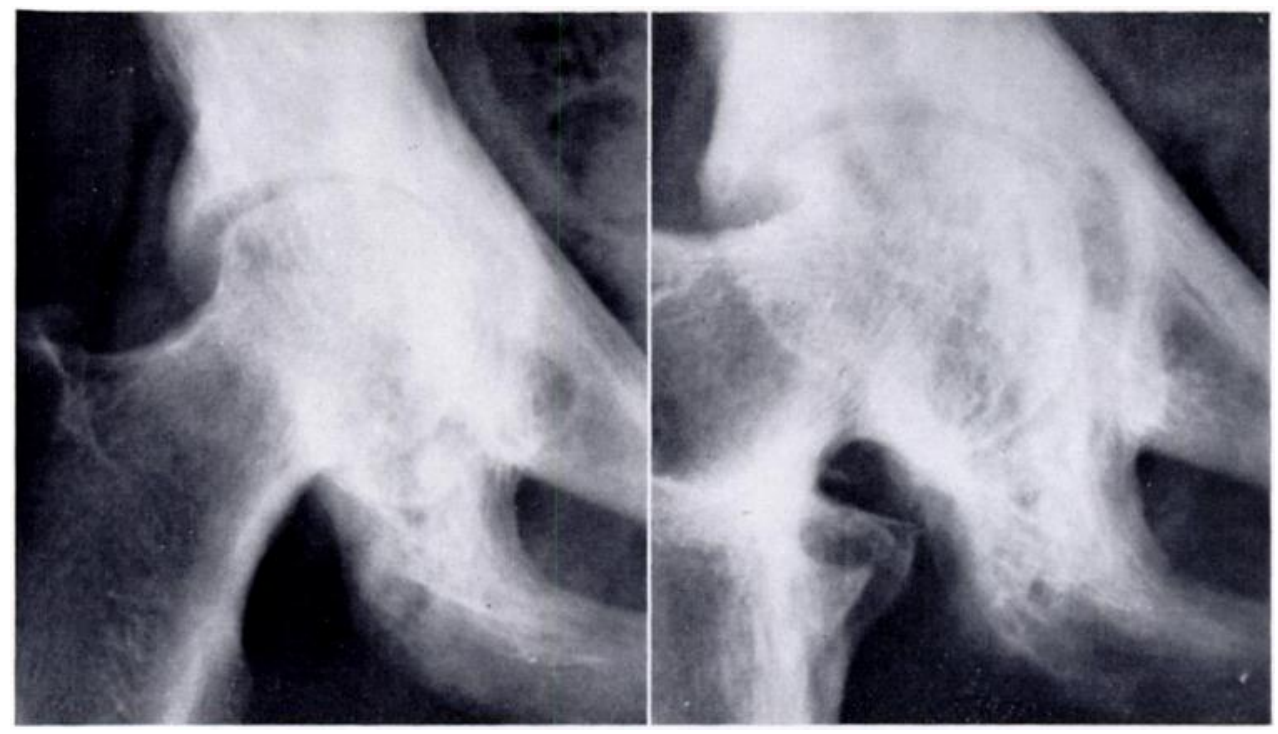

Fig. 3

Radiographs of right hip before operation and three years after operation, showing improvement in joint space.

\section{RESULTS}

Clinical assessment-Before operation, all the patients had severe pain, especially at night, and all used a walking aid. Two patients could walk a mile but the remainder only a few yards. All had a range of hip flexion of 90 degrees, intact outline of the head of the femur and an unbroken Shenton's line; thus they corresponded to Harris and Kirwan's (1964) Group I idiopathic osteoarthrosis.

VOL. 53 B, NO. 4, NOVember 1971 
Thirteen patients (fourteen hips) have been followed for one to seven years with a distribution summarised in Figure 1; one patient was operated upon too recently to be reviewed. All the patients lost their nocturnal pain, seven lost all pain, and four reported much improvement. The pain by day was worse in two. Passive flexion, measured in the conscious patient, was improved in three, unchanged in nine and diminished in two. The gait improved in all but one patient; six dispensed with walking aids. In the two failures one patient was followed for one year and the other for seven.

TABLE II

Results of Osteotomy in Paget's Disease

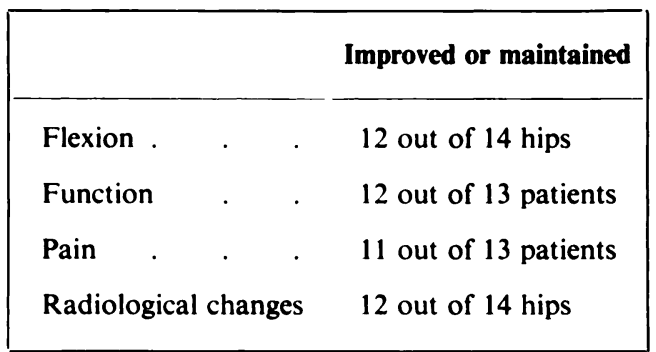

TABLE III

Results Of OSTeOtomy for EARly Osteoarthrosis (Group I, Harris and Kirwan 1961)

\begin{tabular}{|c|c|c|}
\hline & & $\begin{array}{l}\text { Improved or maintained } \\
\text { (per cent) }\end{array}$ \\
\hline Flexion & . & 70 \\
\hline Function & . $\quad$. & 90 \\
\hline Pain & . & 95 \\
\hline \multicolumn{2}{|c|}{ Radiological changes } & 90 \\
\hline
\end{tabular}

Radiological features-All fourteen hips were in Chambers and Pearson (1970) Group III. Nine showed protrusio. There was no correlation between bone texture and the presence or absence of increased density on the one hand and the incidence of protrusio on the other. Eight of the fourteen hips showed radiological evidence of improvement after the osteotomy, with increased joint space and diminution of cysts and osteophytes (Figs. 2 and 3); four were unchanged and two showed deterioration. The Paget's disease had progressed in one of the two patients showing clinical and radiological deterioration.

The results are summarised in Table II. It will be seen that they are comparable with those in idiopathic osteoarthrosis (Table III). No correlation between various types of Paget's disease and the results of osteotomy has been demonstrated.

\section{SUMMARY}

1. The results of fourteen intertrochanteric osteotomies in thirteen patients with painful arthrosis of the hip with Paget's disease of the related bones have been analysed.

2. The findings suggest that osteotomy carried out in this condition before the femoral head collapses has much the same prognosis as osteotomy carried out at a similar stage of idiopathic osteoarthrosis.

I wish to thank the consultant staff of the Royal National Orthopaedic Hospital for permission to study their cases. The illustrations were prepared by the Department of Medical Photography of the Institute of Orthopaedics. I am indebted to Dr E. Allen for his help in the interpretation of the radiographs and to Mr K. I. Nissen and $\mathrm{Mr}$ H. Jackson Burrows for help in the preparation of this paper.

\section{REFERENCES}

Chambers, G. M., and Pearson, J. R. (1970): Femoral Osteotomy in Paget's Disease Affecting the Hip Joint. British Journal of Clinical Practice, 24, 107.

Fairbank, H. A. T. (1950): Atlas of General Affections of the Skeleton. 15. Paget's Disease. Journal of Bone and Joint Surgery, 32-B, 253.

Harris, N. H., and Kirwan, E. (1964): The Results of Osteotomy for Early Primary Osteoarthritis of the Hip. Journal of Bone and Joint Surgery, 46-B, 477.

Nicoll, E. A., and Holden, N. T. (1961): Displacement Osteotomy in the Treatment of Osteoarthritis of the Hip. Journal of Bone and Joint Surgery, 43-B, 50.

Pygotr, F. (1957): Paget's Disease of Bone. The Radiological Incidence. Lancet, i, 1170. 